\title{
Micro methods and micro apparatus for chemical pathology with special reference to paediatrics
}

\author{
BARBARA E. CLAYTON AND P. JENKINS
}

From the Institute of Child Health and the Hospital for Sick Children, Great Ormond Street, London

SYNOPSIS This article describes methods and apparatus which permit the estimation of a particular substance without requiring more blood than can conveniently and safely be removed from a child by capillary puncture. No reference will be made to the use of methods on the Technicon AutoAnalyzer as that machine is not yet generally geared to paediatric work, although a few centres have made their own modifications to permit certain methods to be performed on capillary samples of blood.

The methods currently in use at the Hospital for Sick Children have been evolved over the years and do not belong to any particular 'system'. Their adoption has frequently been governed by a need for a micro method coupled with financial stringency, and we feel that most of our basic routine methods are applicable to general routine laboratories.

In any laboratory considering the introduction of a paediatric chemical pathology service, we would recommend the initial review of all existing laboratory procedures to see whether smaller samples could be used without requiring special apparatus or training of staff. In most hospitals paediatric beds form a small minority of those serviced by a laboratory, and it is unreasonable to expect a busy laboratory to devote any extensive portion of effort in maintaining methods which are infrequently demanded, particularly if they duplicate existing methods. Nevertheless, the availability of a comprehensive paediatric chemical pathology service allows of significant improvement in the treatment and survival of infants and young children.

Many laboratories make excessive demands for blood samples even for adult patients. As an example, in some laboratories a $\mathbf{1}$ in $\mathbf{5 0}$ plasma dilution for the estimation of potassium, using the EEL flame photometer, is made by diluting $0.5 \mathrm{ml}$. plasma to $25.0 \mathrm{ml}$.; of this dilution only a few millilitres are used in the actual estimation, wasting approximately $90 \%$ of the patient's plasma. A separate dilution is usually made for the estimation of sodium. It is possible to obtain five or six readings on $2 \mathrm{ml}$. of a dilution using an EEL flame photometer with a correctly adjusted atomiser. This allows the estimation of both sodium Received for publication 21 December 1965. and potassium on only $20 \mu \mathrm{l}$. of plasma, using a 1 in 100 dilution. Published colorimetric techniques in some standard texts still give volumes suitable for use in a direct-vision colorimeter fitted with macrocells, instead of the small amounts required for modern photoelectric colorimeters.

The more widespread use of micro methods has been hindered by the feeling among many workers that these methods require exotic facilities. We would agree with Natelson (1961) that 'these methods belong to the routine laboratory and not to a special laboratory set up for the purpose'. To this we would add that, by careful choice, methods permitting of a degree of accuracy of the same order as that of macro methods can be used for both adult and paediatric patients.

As well as Natelson (1961), Wilkinson (1960), O'Brien and Ibbott (1962), and Wootton (1964) have published textbooks giving methods suitable for use in most laboratories. Various 'systems' of microanalysis have been described, including those of Conway (1951), Goldenberg (1956), Sanz (1957), Saifer, Gerstenfeld, and Zymaris (1958), Seligson (1959), and Walter and Gerarde (1964). Reinouts van Haga and Wael (1961) have reviewed most types of apparatus available for micro methods.

Ultramicro systems are available commercially (a, b, c). ${ }^{1}$ We have personal experience of (a) only and agree with O'Brien, Ibbott, and Pinfield (1961) and Campbell, Comfort, and Bell (1962), who have reported on their experience with type (a) and also type (b). Although we feel that a system of this nature can in theory provide a useful paediatric service,

${ }^{1}$ Letters in parentheses throughout this article refer to the list of commercial references at the end (page 297). 
we have been disappointed in the results of our efforts to introduce the system into routine use. Constant practice is required to obtain reproducible and accurate results. We have found it necessary to modify the colorimetric methods so that sufficient solution is available to enable colorimeter readings to be made in duplicate in order that errors due to trapped air bubbles, incomplete filling of the cuvette, and 'sticking' of the galvanometer can be detected. In addition the amount of drift on the colorimeters we have tried requires that the zero be checked between each reading. We like, and use, the Sanz type pipettes throughout the laboratory, independently of the rest of the system, but think their accuracy should be checked before use. We find it convenient and cheap to make and calibrate our own Sanz pipettes using a balance sensitive to $0.2 \mathrm{mg}$., although a more sensitive balance would be better. No doubt it is a satisfactory system if highly skilled technicians can be left in peace to work it (Stevens, 1965); this cannot be the situation in many laboratories where there is a high proportion of unqualified staff and very little peace.

\section{COLLECTION OF BLOOD FOR MICRO-ANALYSIS}

The capillary/venous difference which exists for many substances makes the simultaneous use of both methods of collection in any patient unwise, as difficulties may arise in interpreting consecutive results. Contamination of the specimen from the skin by tissue fluids and haemolysis can be reduced to tolerable proportions by careful preparation and technique. The loss of $\mathrm{CO}_{2}$, with the consequent shift of chloride, is almost impossible to prevent but surprisingly consistent and reliable results can be obtained even from badly dehydrated patients. While there is no doubt that better collections are obtained when a suitably sharpened Hagedorn needle is used, some commercially available stylettes can be used successfully, although rather less blood is obtained (d). A particularly detailed account of capillary blood collection is given by Wilkinson (1960). A partially closed system which minimizes exposure of blood to air can be used if required. The necessary device is available commercially (e).

The procedure described by Natelson (1951), although convenient for individual cases, especially if the lobe of the ear has to be used, is in our experience less convenient when large numbers of blood samples have to be handled in batches.

When possible, the use of plasma is preferable to using serum, as the yield is greater and this is of importance when minimum amounts of blood are being collected. The collection of capillary blood requires practice and is time-consuming. We find it convenient to employ part-time ex-nurses or nurser爱 nurses for this purpose, in addition to the tech? nicians who are also trained to collect blood.

\section{APPARATUS}

The wide variety of apparatus for micro-analys described in the literature tends to confuse the news comer in this field. As much of this apparatus hais been developed to overcome difficulties experienced. in particular laboratories it is best initially to con? centrate on a few types generally applicable. This is particularly true of pipettes, which should be restricted to two or three types only.

TUBES Two sizes of heavy-walled, rimless bor $q_{-}^{c}$ silicate glass tubes, $75 \times 10 \mathrm{~mm}$. and $100 \times 16 \mathrm{~mm}$ i will cover most general requirements. We prefer to avoid the use of stoppered glass tubes unless essentia? due to the difficulties of cleaning the ground-glass joint. Disposable polystyrene tubes holding $2.5 \mathrm{mR}$ are available with polythene stoppers (f) and are compatible with most reagents; these tubes can als $\vec{b}$ be obtained in polythene and polypropylenes Smaller disposable polythene and polypropylenes tubes of $0.4 \mathrm{ml}$. and $0.55 \mathrm{ml}$. capacity with stoppero are also available (g). The use of cheap disposablo tubes greatly reduces the problems of contaminatio and of dealing with an unexpectedly heavy worf load.

Plastic tubes should be protected from atmospheri $\overrightarrow{\vec{\sigma}}$ contamination before use, as, due to the electrostatie charge which is frequently present, they are particu larly prone to this form of contamination. Polythene bags are very suitable for such storage. If obtained from a reliable source these tubes are ready for use as supplied. They can be incinerated after use.

Mixing presents difficulties in small tubes and mechanical aid is recommended. The glass and largers sized plastic tubes can be mixed on a vortex mixes (h) and the smaller plastic tubes on a 1 in. cube of polythene mounted on the shaft of a small electrio motor.

\section{CLEANING OF GLASSWARE}

Cleaning glassware is of the utmost importance, as amounts of contamination which are tolerable in macro procedure represent a serious hazard in micre work due to the relatively greater surface area. Where possible, disposable apparatus should be used and $\vec{q}$ standard procedure used for all glassware. Tubes should be discarded into detergent, taking care that the tube is filled with liquid, for a pre-wash soaking? After several hours the tubes should be well brusheq out and rinsed under a running tap. Chicken wing 
feathers made excellent brushes for the small tubes with no risk of scratching. A further shorter soaking in fresh detergent (i) followed by a thorough brushing and rinsing with tap water is followed by soaking for one to two hours in $10 \% \mathrm{v} / \mathrm{v}$ hydrochloric acid. The acid is removed by rinsing six times with tap water and three times with de-ionized water. We prefer to avoid the use of chromic sulphuric acid mixture due to the difficulty of removing traces of chromium from the glass, and if glassware is to be used for trace metal analysis we prefer to soak it in strong solutions $(10-50 \%)$ of nitric acid followed by rinsing in distilled water only.

\section{PIPETTES}

If care is taken to ensure that the pipette can deliver to the bottom of the tube, the smaller sizes of those pipettes normally found in chemical pathology laboratories will be found suitable for the addition of reagents and transfer of supernatants in many cases. The pulling out and/or bending of the tip of a between-marks pipette can be of assistance in adding reagents to the contents of a tube. The smaller sizes, 0.02 and $0.05 \mathrm{ml}$. pipettes calibrated to contain, are useful for the addition of samples. They should be operated with a syringe attachment rather than a rubber mouthpiece and the method of operating this type of pipette is well described by Wilkinson (1960) and by O'Brien and Ibbott (1962). The type of syringe described by them can be improved by the use of a $2 \mathrm{ml}$. all-glass syringe, with the nozzle removed. A 2 in. length of thick-walled opaque vinyl tubing $(j)$ is fitted over the barrel, which should be warmed over a bunsen to assist in fitting the tube for about one-third of its length. Rubber bands should be wound tightly round the remainder of the vinyl tubing to give the bore a slightly conical shape, thus enabling it to grasp a wider range of pipette sizes. The plunger should be lubricated with vaseline.

Apart from these, we prefer to use only two types of specialized pipettes:-

1 Constriction pipettes, calibrated to deliver: selfzeroing pipettes of the constriction type are available commercially $(\mathrm{k})$. Blockage of the constriction is always a problem with this type of pipette and they must be washed out on a vacuum pump with water and acetone immediately after use.

$2 \mathrm{~A}$ better alternative is the overflow type of pipette which is available commercially (a and b), though extremely easy to make and calibrate in the laboratory. This type of pipette has proved very suitable for general use, and most laboratory staff have little difficulty in operating them.
BURETTES

Two types are available:-

1 Displacement burettes in which the titrant is displaced by the movement of a plunger of known dimensions, the distance the plunger moves being measured by a micrometer. This type of burette is very accurate, as the plunger can be accurately machined, but it is usually somewhat tedious to use and fill. The use of larger reservoirs, with the plunger entering through a silicone rubber gasket, and of dial type micrometers calibrated directly in microlitres, overcomes some of these difficulties (1), but such models are at present somewhat expensive and may introduce errors due to movement of the sealing gasket. The plunger may either displace the titrant directly or via mercury or liquid paraffin.

2 Calibrated capillary burettes may have the calibrated capillary either horizontal $(m)$ or vertical (n). The former is preferable as errors due to drainage are less. The titrant may be displaced by gravity or by a plunger, the latter operating via mercury or liquid paraffin.

For the addition of small quantities of relatively concentrated titrants the displacement type is to be preferred. For volumes greater than $0.5 \mathrm{ml}$. neither has, in our experience, much advantage over a 1 or $2 \mathrm{ml}$. burette to BSS 846, fitted with an extension to the tip formed by drawing out a length of polythene tubing to a fine capillary. The tip should be slightly roughened with fine emery paper to ensure adhesion of the capillary. Deliveries of titrant with microburettes of any type should always be made with the tip just below the surface to avoid errors due to drops forming.

Automatic apparatus for dispensing and diluting small volumes are available $\left(n_{1}\right.$ and $\left.n_{2}\right)$. We have no personal experience of their use.

\section{CENTRIFUGES}

Filtration should usually be avoided in micro work since losses occur from retention of filtrate and evaporation. Centrifugation is usually satisfactory provided that care is taken to avoid drawing up any particles which are held up by surface tension. Most macro centrifuges can be fitted with adaptors to take micro tubes in the standard buckets.

\section{SPECTROPHOTOMETERS AND COLORIMETERS}

The volume required to fill the cuvettes of these instruments is usually the overall deciding factor in the amount of specimen taken originally. One instrument (a) is specifically manufactured for use with small volumes $(0 \cdot 1 \mathrm{ml}$.) but for satisfactory operation 
we find that all solutions have to be read in duplicate and the zero checked between each reading.

Most spectrophotometers can be fitted with micro cells which give a light path of $1 \mathrm{~cm}$. for about $0.5 \mathrm{ml}$. If sufficient sensitivity is available in the light detector this volume can be further reduced by masking. The built-in lenses and slit holders of the Unicam SP500 (o) are particularly useful for this purpose. Some filter absorptiometers and diffraction grating spectrophotometers can be similarly modified. Readings of test, blank, and standards should always be made in the same cuvette against a reference cuvette filled with a suitable liquid, usually distilled water. This precaution is particularly necessary when reading solutions of low optical density.

\section{APPARATUS FOR ESTIMATING ACID-BASE BALANCE}

The Natelson gasometer (p) provides not only an excellent micro-procedure for estimating $\mathrm{CO}_{2}$ content, but saves a great deal of time. We would recommend its general adoption in any laboratory. An Astrup machine for $p \mathrm{H}$ and $\mathrm{pCO}_{2}(\mathrm{q})$ is essential if a service has to be provided for maternity hospitals or paediatric cardiac beds.

\section{COMMONLY REQUIRED ESTIMATIONS}

The estimations most commonly required for paediatric patients are shown in Table I. References are given to methods which have been modified to suit our own requirements.

\section{NORMAL VALUES DURING CHILDHOOD}

For very detailed accounts of normal values in children it is necessary to consult original articles, but many useful summaries are given in 'The' physiology of the newborn infant', by C. A. Smit五 (Blackwell Scientific Publications, Oxford, 1959) 'Diagnostic tests in infants and children', by Behrendt (Henry Kimpton, London, 1962); Donal $\$$ Paterson's 'Sick children, diagnosis and treatment edited and revised by R. Lightwood and F. S. W Brimblecome (Cassell, London, 1963).

\section{CONCLUSION}

Without excessive financial outlay on apparatus and staff, it should be possible for a general routin laboratory to provide a service for the small per? centage of beds usually devoted to children in genera hospitals.

We recommend that the following steps be taken:-

1 Laboratory staff (not necessarily techniciansf should be trained to collect satisfactory samples of blood by heel or finger prick. This technique requires practice and is harder than it looks. Satisfactor specimens of capillary blood will never be providet by the medical staff except for the occasional bloof sugar estimation.

2 The methods already in use in the department should be reviewed. In many procedures much of the sample is wasted. With a little adaptation, this wastage can be avoided so that the methods are suitable for capillary samples.

3 A few special pieces of apparatus should be purchased, namely, Sanz pipettes, a microcell for the spectrophotometer, a Natelson gasometer.

4 The introduction of the type of methods listed ip Table I should be considered. These do not call for any unusual skill on the part of the technical staff.

The introduction of an ultramicro system is a ver

\section{T A B LE I}

\begin{tabular}{|c|c|c|}
\hline \multirow[b]{2}{*}{ Estimation } & \multicolumn{2}{|c|}{ ROUTINE ESTIMATIONS ADAPTED TO MICRO METHODS } \\
\hline & Amount & $\begin{array}{l}\text { Modification to Micro Method Used at the Hospital for Sick Children, Great Ormon } \\
\text { Street, London }\end{array}$ \\
\hline Sodium and potassium & Plasma, $20 \mu \mathrm{l}$. & EEL flame photometer \\
\hline $\mathrm{CO}_{2}$ content & Plasma, $30 \mu \mathrm{l}$ & $\begin{array}{l}\text { Natelson gasometer (method handbook supplied with machine) ( } p \mathrm{H} \text { and } \mathrm{PCO}_{2}-\mathrm{Astru} \\
\text { machine) }\end{array}$ \\
\hline Chloride & Plasma, $50 \mu l$. & Van Slyke, D. D., and Hiller, A. (1947). J. biol. Chem., 167, 107. \\
\hline Urea & Plasma, $10 \mu \mathrm{l}$. & $\begin{array}{l}\text { Kaplan, A. (1965). In Standard Methods of Clinical Chemistry, vol. 5, edited by S. Mei } \\
\text { p. 249. Academic Press, New York. }\end{array}$ \\
\hline Glucose & Blood, $20 \mu \mathrm{l}$. & Huggett, A. St. G., and Nixon, D. A. (1957). Lancet, 2, 368. \\
\hline Bilirubin & Plasma, $20 \mu \mathrm{l}$. & $\begin{array}{l}\text { MacDonald, R. P. (1965). In Standard Methods of Clinical Chemistry, vol. 5, edited } \\
\text { S. Meites, p. 65. Academic Press, New York. }\end{array}$ \\
\hline Calcium & $0.1 \mathrm{ml}$. & Eppendorf flame photometer \\
\hline & Plasma, $0.1 \mathrm{ml}$. & Wilkinson, R. H. (1957). J. clin. Path., 10, 126. (Chelation method with murexide as indica \\
\hline anic phos & Plasma, $0.1 \mathrm{ml}$. & Gomori, G. (1942). J. Lab. clin. Med., 27, 955. \\
\hline Alkaline phosphatase & Plasma, $0.1 \mathrm{ml}$. & King, E. J., and Armstrong, A. R. (1934). Canad. med. Ass. J., 31, 376. \\
\hline Protein & Serum, $5 \mu 1$. & $\begin{array}{l}\text { King, E. J., and Wootton, I. D. P. (1956). For differential protein. In Biuret Method Micr } \\
\text { analysis in Medical Biochemistry, 3rd ed., p. 57. Churchill, London. }\end{array}$ \\
\hline $\begin{array}{l}\text { Protein (paper } \\
\text { electrophoresis) }\end{array}$ & Serum, $20 \mu 1$. & Flynn, F. V., and De Mayo, P. (1951). Lancet, 2, 235. \\
\hline $\begin{array}{l}\text { Creatinine } \\
\text { Cholesterol } \\
\text { Transaminases } \\
\text { Sweat electrolytes }\end{array}$ & $\begin{array}{l}\text { Plasma, } 0.5 \mathrm{ml} \text {. } \\
\text { Serum, 0.1 ml. } \\
\text { Serum, 0.1 ml. } \\
\text { Sweat, } 100 \mathrm{mg} \text {. }\end{array}$ & $\begin{array}{l}\text { Owen, J. A., Iggo, B., Scandrett, F. J., and Stewart, C. P. (1954). Biochem. J., 58, } 426 . \\
\text { Carr, J. J., and Drekter, I. J. (1956). Clin. Chem., 2, 353. } \\
\text { King, J. (1958). J. med. Lab. Technol., 15, } 17 . \\
\text { McKendrick, T. (1962). Lancet, 1, 183. }\end{array}$ \\
\hline
\end{tabular}


different undertaking. Specialized apparatus must be purchased, highly trained staff must be left in peace and quiet to carry out the estimations, and contamination must be avoided. In general, technicians in training are not suitable for staffing as it is necessary to be in continuous practice if accurate results are to be obtained. The adoption of an ultramicro system by a busy routine laboratory servicing only a few paediatric beds is not recommended by us at present.

We should like to thank Mr. M. Snook, A.I.M.L.T., for his help in preparing this manuscript.

\section{COMMERCIAL REFERENCES}

These are given for convenience only and should not be taken as implying the unsuitability of similar apparatus offered by other suppliers.

(a) Beckman/Spinco ultramicro analytical system. Beckman International Division, 2500 Fullerton Road, Fullerton, California. U.K. distributors: Hawkesley \& Sons Ltd., 16a North Road, Lancing, Sussex.

(b) Coleman Ultramicro Analytical Program. Coleman Instruments Inc., 42 Madison Street, Maywood, Illinois.

(c) Mikrolitersystem 'Eppendorf R'. Netheler \& Hinz, GmbH, 2 Hamburg-Wellinsbüttel. U.K. distributors: V. A. Howe Ltd., 46 Pembridge Road, London, W.11.

(d) Armolet sterile disposable lancet. Armour Pharmaceutical Co. Ltd., Eastbourne, Sussex.

(e) Rasmussen Disposable Blood Collector. Oakdale Co., P.O. Box 1111, South Bend, Indiana, 46624.

(f) LP3 Polystyrene tubes. Luckham Ltd., 591-3 Kingston Road, Raynes Park, London, S.W.20.

(g) 400 and 500 microlitre polythene and polypropylene tubes. Milian Instruments S.A., 26 Boulevard Helvetique, Geneva. U.K. distributors: Hawksley \& Sons Ltd., 16a North Road, Lancing, Sussex.

(h) 'Whirlimix' vortex mixer. Messrs. Scientific Industries Ltd., Central Chambers, Hendon Central, London, N.W.4.

(i) Diversey Pyroneg. Diversey (U.K.) Ltd., 42-46 Weymouth Street, London, W.1. (j) TX-470 PVC tubing, opaque green elastic, laboratory grade. Messrs. A. Gallenkamp \& Co. Ltd., Christopher Street, London, E.C.2.

(k) Pedersen Automatic Constriction Pipettes. H. E. Pedersen, 37 Peter Bangsvej, Copenhagen F, Denmark.

(1) Digi-pet ultra micro burette and pipette. Manostat Corpn. 20 N. Moore St., New York 13.

(m) Spinco Microburette, horizontal displacement type. Accurate to $0.01 \mu \mathrm{l}$., capacity $200 \mu \mathrm{l}$. Hawksley \& Sons, 16a North Road, Lancing, Sussex.

(n) Microburette, vertical motorized displacement type. Accurate to $0.1 \mu \mathrm{l}$., capacity $3.4 \mathrm{ml}$. American Instrument Co., 8030 Georgia Ave., Silver Springs, Maryland, U.S.A.

$\left(n_{1}\right)$ Auto-diluter. Hook \& Tucker Ltd., 301 Brixton Road, London, S.W.9.

$\left(\mathrm{n}_{2}\right)$ A similar apparatus is made by Griffin \& George Ltd., Ealing Road, Alperton, Middlesex.

(o) Unicam SP 500. Messrs. Unicam Instruments Ltd., York Street, Cambridge.

(p) Natelson gasometer. Scientific Industries Ltd., Central Chambers, Hendon Central, London, N.W.4.

(q) Astrup. V. A. Howe Ltd., 46 Pembridge Road, London, W.11

\section{REFERENCES}

Campbell, D. J., Comfort, D., and Bell, R. E. (1962). Amer. J. clin. Path., 38, 323.

Conway, E. J. (1951). Microdiffusion Analysis and Volumetric Error. 3rd ed. Crosby Lockwood, London.

Goldenberg, H. (1956). Anal. Chem., 28, 1003.

Natelson, S. (1951). Amer. J. clin. Path., 21, 1153.

(1961). Microtechniques of Clinical Chemistry, 2nd ed. Thomas, Springfield, Illinois.

O'Brien, D., and Ibbott, F. A. (1962). Laboratory Manual of Pediatric Micro- and Ultramicro-Biochemical Techniques, 3rd ed. Harper and Row, New York.

$\longrightarrow$, and Pinfield, A. (1961). Clin. Chem., 7, 521

Reinouts van Haga, P., and Wael, J. de (1961). Advanc. clin. Chem., 4, 321.

Saifer, A., Gerstenfeld, S., and Zymaris, M. C. (1958). Clin. Chem., $4,127$.

Sanz, M. C. (1957). Ibid., 3, 406.

Seligson, D. (1959). Ibid., 5, 320.

Stevens, J. F. (1965). J. med. Lab. Technol., 22, 47

Walter, A. R., and Gerarde, H. W. (1964). Clin. Chem., 10, 509.

Wilkinson, R. H. (1960). Chemical Micromethods in Clinical Medicine. Thomas, Springfield, Illinois.

Wootton, I. D. P. (1964). Micro-Analysis in Medical Biochemistry, 4th ed. Churchill, London. 